\title{
HOSPITABLENESS E SERVICESCAPE NA HOSPITALIDADE NO CONTEXTO DO VAREJO NA CIDADE DE SÃO PAULO
}

\author{
Auhana Nardini Margutti \\ Mestre em Hospitalidade \\ Universidade Anhembi Morumbi \\ São Paulo / SP. Brasil. \\ auhana.nardini@yahoo.com.br \\ Roseane Barcellos Marques \\ Professora do Programa de Pós-graduação Mestrado e Doutorado em Hospitalidade na Universidade Anhembi \\ Morumbi \\ Doutorada em Administração Pública e Governo pela FGV-EAESP \\ Universidade Anhembi Morumbi \\ São Paulo / SP. Brasil. \\ roseanebmarques@yahoo.com.br \\ (iD) Claudio José Stefanini \\ Professor do Programa de Pós-graduação Mestrado e Doutorado em Hospitalidade na Universidade Anhembi \\ Morumbi \\ Doutorado em Administração pelo Centro Universitário da FEI \\ São Paulo / SP. Brasil. \\ cjstefanini@gmail.com
}

\section{Resumo}

Objetivo do estudo: Investigar as características hospitaleiras e o servicescape presentes no ato da interação social anfitrião-cliente promovidas no interior dos estabelecimentos do varejo, na cidade de São Paulo.

Metodologia/Abordagem: Metodologicamente, é uma pesquisa quantitativa, tendo como instrumento de coleta de dados a técnica survey, por meio de questionário desenvolvido no Google Forms. A análise dos dados foi realizada a partir do software SMARTPLS 3, para modelagem da equação estrutural que explica as relações entre múltiplas variáveis, examinando as equações capazes de descreverem as relações entre os constructos servicescape, hospitableness, hospitalidade.

Originalidade/Relevância: Os desafios competitivos enfrentados pelos anfitriões dos estabelecimentos comerciais, na busca por melhores resultados, fizeram com que a hospitalidade fosse percebida como um aspecto de diferenciação do produto/serviço prestado.

Principais resultados: Os resultados sugerem que a percepção de hospitalidade se confirma estatisticamente em todas as hipóteses, especialmente hospitableness. Permitem considerar que há relação entre as características do ambiente físico e as hospitaleiras em estabelecimentos como acomodação, restaurantes e lojas de varejo na Cidade de São Paulo.

Contribuições teóricas/Metodológicas: Este estudo adiciona à literatura emergente sobre práticas de hospitalidade no setor de varejo, em particular, no varejo de serviços.

Palavras-chave: Hospitalidade. Hospitableness. Servicescape. Varejo. 
Margutti, A. N., Marques, R. B., \& Stefanini C. J. (set./dez. 2020). Hospitableness e servicescape na hospitalidade no contexto do varejo na cidade de São Paulo

\title{
Cite como
}

American Psychological Association (APA)

Margutti, A. N., Marques, R. B., \& Stefanini C. J. (set./dez. 2020). Hospitableness e servicescape na hospitalidade no contexto do varejo na cidade de São Paulo. PODIUM Sport, Leisure and Tourism Review, São Paulo, 9(3), 370-407. https://doi.org/10.5585/podium.v9i3.14840.

\section{HOSPITABLENESS AND SERVICESCAPE IN HOSPITALITY IN THE CONTEXT OF RETAIL IN THE CITY OF SAO PAULO}

\begin{abstract}
Objective of the study: To investigate the hospitable characteristics and servicescape present in the act of social host-client interaction promoted inside retail establishments, in the city of São Paulo.

Methodology/Approach: Methodologically, it is a quantitative research, with data collection instrument the survey technique, through a questionnaire developed in Google Forms. Data analysis was performed using the SMARTPLS 3 software, a model of the structural equation that explains the relationships between multiple variables, examining the equations capable of describing the relationships between the constructos servicescape, hospitableness, hospitality.

Originality/Relevance: The competitive challenges faced by hosts of commercial establishments in the search for better results made hospitality perceived as an aspect of differentiation of the product / service provided.

Main results: The results suggest that the perception of hospitality is statistically confirmed in all cases, especially hospitableness. They allow us to consider that there is a relationship between the characteristics of the physical environment and the hospitable ones in establishments such as accommodation, restaurants and retail stores in the City of São Paulo.
\end{abstract}

Theoretical/Methodological Contributions: This study adds to the emerging literature on hospitality practices in the retail sector, in particular, retail services

Keywords: Hospitality. Hospitableness. Servicescape. Retail.

\section{HOSPITABLENESS Y SERVICESCAPE EN HOSPITALIDAD EN EL CONTEXTO MINORISTA EN LA CIUDAD DE SAO PAULO}

\section{Resumen}

Objetivo del estudio: Investigar las características hospitalarias y el paisaje de servicios presentes en el acto de interacción social anfitrión-cliente promovido dentro de los establecimientos comerciales, en la ciudad de São Paulo.

Metodología/Enfoque: Metodológicamente es una investigación cuantitativa, utilizando la técnica de la encuesta como instrumento de recolección de datos, a través de un cuestionario desarrollado en Google Forms. El análisis de datos se realizó utilizando el software SMARTPLS 3, para modelar la 
ecuación estructural que explica las relaciones entre múltiples variables, examinando las ecuaciones capaces de describir las relaciones entre el paisaje de servicios, la hospitalidad, los constructos de la hospitalidade

Originalidad/Relevancia: Los desafíos competitivos que enfrentan los anfitriones de establecimientos comerciales en la búsqueda de mejores resultados hicieron que la hospitalidad se percibiera como un aspecto diferenciador del producto / servicio brindado.

Principales resultados: Los resultados sugieren que la percepción de la hospitalidad se confirma estadísticamente en todos los casos, especialmente la hospitalidad. Nos permiten considerar que existe una relación entre las características del ambiente físico y las hospitalarias en establecimientos como alojamiento, restaurantes y tiendas minoristas en la Ciudad de São Paulo.

Contribuciones teóricas / metodológicas: este estudio se suma a la literatura emergente sobre prácticas de hotelería en el sector minorista, en particular, en el comercio minorista de servicios.

Palabras clave: Hospitalidad. Hospitableness. Servicescape. Minorista.

\section{Introdução}

A interação interpessoal, inerente à hospitalidade, ocorre nos mais diversos ambientes, inclusive, nas atividades comerciais em estabelecimentos do varejo quando há o encontro entre colaborador e cliente. Nesse instante, as características pessoais do colaborador, cognitivamente, são acionadas e tendem a produzir atitudes e comportamentos hospitaleiros, se percebidos como simpáticos pelos clientes ou hostis, quando antipáticos. Dessa forma, criar momentos memoráveis nos estabelecimentos comerciais, tem-se como expectativa a produção de sensações e emoções que possam ampliar o desempenho empresarial (Alves \& Marques, 2019).

A hospitalidade se desenvolve no indivíduo nos primeiros contatos interpessoais em sociedade e nas mais diferentes situações em que houver interação entre um receptor e um acolhido, mesmo que esse encontro tenha como objetivo a troca de mercadoria por unidade monetária (Grinover, 2002). A literatura clássica da hospitalidade, de origem socioantropológica, enfatiza o caráter genuíno dessa relação. Ela estabelece uma distância entre as relações sociais sem interesses ulteriores das relações sociais em ambientes comerciais com objetivos previamente definidos (Telfer, 2004). Neste artigo, assume-se que o encontro interpessoal no espaço empresarial produz uma interação entre indivíduos cuja qualificação resultará, ou não, em experiências memoráveis. 
A preocupação com a experiência do consumidor (Kotler, Kartajaya \& Setiawn, 2017), no interior de uma loja é o de manter o percurso do consumidor, isto é, que ele estabeleça um contato efetivo de compra e recompra dos produtos/serviços dessa loja. A divergência de aspirações entre o desejo do consumidor e a forma como a loja está estruturada para atender esse desejo culmina com a interrupção desse trajeto, visto que ele está em busca de uma experiência superior ou memorável.

Em um cenário competitivo, a hospitalidade surge como uma maneira de influenciar na experiência dos clientes em diferentes esferas, envolvendo as características do ambiente físico que foram pensadas para recebê-lo, como também os funcionários que o atendem e a experiência desde a sua chegada até o momento da despedida. A discussão sobre as características hospitaleiras empregadas nos espaços com oferta de serviços tende a estreitar a relação entre anfitrião-cliente e anfitrião-funcionário nas atividades comerciais da hospitalidade.

A cultura da hospitalidade presente em organizações comerciais, governamentais e sem fins lucrativos se expande para as organizações prestadoras de serviços em ambientes comerciais, impondo especial preocupação ao local onde essas relações serão estabelecidas (Pizam \& Tasci, 2019). A maneira como se desenha o interstício entre a experiência do cliente em um estabelecimento, a relação que se estabelece entre o cliente e o anfitrião, a habilidade que esse anfitrião possui em ser hospitaleiro e o cuidado com o espaço físico em que serve de cenário para o encontro hospitaleiro (Gotman, 2009; Lashley, 2004; Camargo, 2015; Grinover, 2002; Reimer \& Khuen, 2005; Bitner, 1992; Kotler, 2000; Prasad \& Seshanna, 2015; Las Casas, 2004), pautam a discussão desta pesquisa que tem por objeto de estudo os estabelecimentos de varejo na cidade de São Paulo.

A cidade de São Paulo, fundada em 25 de janeiro de 1554, desenvolve-se com a criação de infraestrutura, rodovias, monumentos e museus entre outras institucionalidades criadas para atender sua população que tem na sua formação influências socioculturais de imigrantes das mais diferentes origens, o que contribuiu na construção de uma cidade cosmopolita (Cidade de São Paulo, 2019).

Os dados do Instituto Brasileiro de Geografia e Estatística ([IBGE], 2010), revelaram que a metrópole de São Paulo é formada por 10.886.518 habitantes, muitos deles consumidores de estabelecimentos do varejo como os meios de hospedagem, restaurantes e lojas comerciais. No Brasil, em 2018, o setor de serviços se destacou no Produto Interno Bruto (PIB), obtendo 
uma alta de $1,1 \%$ em relação ao ano anterior, totalizando $\mathrm{R} \$ 6,8$ trilhões. Isto, corresponde à $75,8 \%$ do PIB, que recebeu influência das atividades comerciais com crescimento registrado de 2,3\% e das atividades imobiliárias com 3,1\% (IBGE, 2010).

A prestação de serviços de hospedagem, alimentação e lojas comerciais também fazem parte do setor de serviços. Na expectativa de compreender a dimensão destas atividades, por meio dos dados do Observatório do Turismo e Eventos, identificou-se 14.026 leitos disponíveis no setor hoteleiro da cidade de São Paulo em 2018. Em pesquisa realizada pelo IBGE (2017), apurou-se 507.412 leitos disponíveis no estado de São Paulo, representando $21 \%$ da oferta nacional. Para o Portal da Cidade de São Paulo (2019), verificou-se a existência de 240 mil lojas, 77 shopping centers e mais de 12 mil restaurantes e bares para atender a população local e os turistas. Contudo, ainda que esta pesquisa não tenha alcançado o total de estabelecimentos comerciais de hospedagem, alimentação e lojas do município em estudo, estes números indicam a relevância do tema e suas implicações práticas e gerenciais.

O objetivo geral deste estudo foi o de investigar as características hospitaleiras e o servicescape presentes no ato da interação social anfitrião-cliente, promovidas no interior dos estabelecimentos do varejo, na cidade de São Paulo. Este objetivo pretendeu responder ao seguinte problema de pesquisa: "Por que a hospitalidade, a hospitableness e o servicescape influenciam a percepção dos clientes dos estabelecimentos de varejo na cidade de São Paulo?"

Para responder a este problema, três hipóteses foram desenvolvidas a partir do levantamento da literatura com base em três constructos: Hospitalidade, Hospitableness e Servicescape e do objeto. Ou seja, estabelecimentos de varejo - hospedagem, alimentação e lojas:

H1: O ambiente físico impacta na percepção de hospitalidade do cliente.

H2: As características hospitaleiras influenciam na percepção de servicescape.

H3: As características hospitaleiras estão diretamente relacionadas à percepção de hospitalidade do cliente.

A abordagem desta pesquisa é de cunho quantitativo, com aplicação de questionário aos frequentadores do varejo (restaurantes, meios de hospedagem e lojas) da cidade de São Paulo, com o intuito de identificar a percepção das características de Hospitalidade, Hospitableness e Servicescape sob perspectiva dos clientes. A análise quantitativa emprega a técnica de modelagem de equações estruturais que, de acordo com Hair, Black, Babin, Anderson e Tathan 
(2009) e aplicado por Stefanini, Alves e Marques (2018), explica as relações entre múltiplas variáveis, examinando a estrutura de interrelações entre uma série de equações que as descrevem entre os constructos.

O artigo está composto por três sessões, além desta introdução. Na primeira sessão, apresenta-se a fundamentação teórica dos constructos Hospitalidade, Hospitableness e Servicescape. Na sequência, os objetos e sua caracterização conceitual, bem como os procedimentos metodológicos da pesquisa. Na terceira sessão, são demonstrados e discutidos os resultados da pesquisa.

Este trabalho coloca em debate o ambiente físico no qual a hospitalidade ocorre e a importância das suas características hospitaleiras no momento da interação anfitrião-cliente.

\section{Revisão da literatura}

\subsection{Hospitalidade}

A hospitalidade está presente nos primeiros contatos dentro de um contexto sociocultural, isso é, quando as relações são criadas. Dessa forma, pode ser aplicada a diferentes situações em que há interação entre o receptor e o acolhido, por exemplo, na realização da troca de mercadoria pela moeda (Grinover, 2002). $\mathrm{O}$ ato de acolher e prestar serviços a alguém que, por qualquer motivo, esteja fora de seu local de domicílio, se traduz em uma relação especializada entre dois protagonistas: quem recebe e aquele que é recebido (Gotman, 2009). Lashley (2004) descreve a hospitalidade como o relacionamento construído entre anfitrião e hóspede, como uma interação que acontece de seres humanos com seres humanos, em tempos e espaços planejados (Camargo, 2004). É um rito de passagem, dádiva temporária de um espaço (Grassi, 2004). Assim, a hospitalidade pode ser considerada uma virtude (Camargo, 2015; Telfer, 2004), sendo esperada quando há o confronto com estranhos, resultando em estreitamento ou afastamento do vínculo social (Camargo, 2015). Nesse sentido, Telfer (2004, p. 54) explica que "a hospitalidade é a oferta de alimentos e bebidas e, ocasionalmente, acomodação para pessoas que não são membros regulares da casa. A ideia central do conceito envolve a partilha da própria casa com terceiros".

Quando vista como um fenômeno humano, permite, através da sua lente social, que as ações dos seres humanos sejam mais bem compreendidas. A forma como os anfitriões recebem as pessoas de fora está relacionada com a cultura da comunidade, que pode ser hospitaleira ou 
gerar uma diferenciação nessa relação (Lashley, Lynch \& Morrison, 2007). No eixo social, a hospitalidade para Camargo (2004), pode ser subdividida em quatro categorias: doméstica, pública, virtual e comercial.

A hospitalidade doméstica, do ponto de vista histórico, é a mais típica e a que envolve maior complexidade no que concerne aos ritos e significados. Consiste no acolhimento proporcionado em meio particular, entre amigos, não necessariamente no ato de hospedar, mas no de receber sem que haja pagamento. Todavia, a hospitalidade pública é aquela que acontece em decorrência do direito de ir e vir e da necessidade de se alcançar as expectativas de interação humana, podendo ser entendida tanto no cotidiano da vida urbana que privilegia os residentes do local como na dimensão turística e na dimensão política, de uma maneira mais ampla, abrangendo a problemática dos migrantes de países mais pobres em direção aos mais ricos. No caso da hospitalidade virtual, o emissor e o receptor da mensagem são, respectivamente, anfitrião e visitante, com todas as consequências que essa relação implica. Camargo (2004) sustenta que a hospitalidade comercial surgiu dentro das modernas estruturas criadas em função do crescimento do turismo e associada à designação habitual de hotelaria e restauração. Sendo realizada apenas mediante a troca monetária, visto que é comercial, nesta categoria se encaixa também o Varejo (Faria \& Torres, 2015).

Por sua vez, Lashley $(2004,2015)$ contextualizou a hospitalidade em três domínios e salientou que a sua experiência concreta apresenta a influência de cada um deles:

- Privado (Lashley, 2004) ou doméstico (Lashley, 2015): a gama de questões associadas à provisão de alimentos, bebidas e hospedagem no lar, bem como o impacto das obrigações do hóspede e do anfitrião;

- Social (Lashley, 2004) que se tornou Cultural (Lashley, 2015): os contextos sociais nos quais a hospitalidade e os atos de hospitableness ocorrem junto com os impactos das forças sociais e dos sistemas de crença relacionados aos processos de produção e consumo de alimentos, bebidas e hospedagem; e

- Comercial (Lashley, 2004) ou profissional (Lashley, 2015): a provisão da hospitalidade como uma atividade econômica que fornece alimentos, bebidas e hospedagem em troca de dinheiro, tendo como objetivo a mais-valia.

No eixo doméstico (Camargo, 2004) e no domínio privado ou doméstico (Lashley, 2004, 2015), destaca-se a complexidade da relação, por possuir ritos, significados e obrigações. 
Camargo (2004) enfatiza que não é, necessariamente, o ato de hospedar, mas, o de receber. Por sua vez, a hospitalidade pública abrange o contexto social mais amplo das interações humanas, inclusive na dimensão política quanto ao recebimento de povos de outras localidades (Camargo, 2004) e, nesse sentido, Lashley $(2004,2015)$ associa o domínio cultural às questões sociais no processo de produção e consumo de alimentos, bebidas e hospedagem. Dessa maneira, Camargo (2004, 2015) e Lashley $(2004,2015)$ convergem ao assumirem que a hospitalidade comercial acontece apenas mediante a troca financeira.

Na visão de Camargo (2004), a hospitalidade comercial surgiu com o desenvolvimento das atividades associadas ao turismo. Entretanto, a experiência da hospitalidade está na intersecção entre os domínios. Por exemplo, em um contexto comercial, para que a experiência seja completa, as obrigações e a distinção dos papéis de anfitrião e de hóspede possuem forte influência na percepção do serviço prestado, sendo visíveis tanto no domínio doméstico ou privado como no público ou social (Lashley, 2015). Na perspectiva de Telfer (2004), no contexto privado, a hospitalidade é ofertada a convidados escolhidos e é movida por interesse próprio. No contexto comercial, essa relação não acontece como em um lar, a hospitalidade não é ofertada, os convidados não são escolhidos e há a preocupação com o bem-estar dos hóspedes. O fenômeno hospitalidade no contexto comercial não é recente na história das civilizações. Os primeiros sinais sobre a hospitalidade comercial apareceram na história da Guerra do Peloponeso, sugerindo que a palavra katagogion assumisse o sinônimo para pensão ou hotelaria (O’Gorman, 2007).

A cultura da hospitalidade pode ser amplamente aplicada às organizações comerciais, governamentais e sem fins lucrativos, expandindo a atenção para as organizações de serviços comerciais (Pizam \& Tasci, 2019). Para que estas relações aconteçam, o local onde elas ocorrem também tem um papel especial (Pizam \& Tasci, 2019). Nesse âmbito, a hospitalidade é oferecida às pessoas que pagam pela utilização do serviço. Se o hospedeiro tiver interesse autêntico pela felicidade do seu hóspede, cobrando um preço razoável pelo o que é oferecido, então, as atividades podem ser denominadas de hospitaleiras (Telfer, 2004).

Camargo (2004) aborda quatro rituais de hospitalidade que devem ser exercidos por toda a sociedade. O primeiro, é o receber, que no ritual de hospitalidade está relacionado com o acolhimento de pessoas que estão fora de seu local habitual. O segundo, refere-se à hospedagem, que pode ser oferecida em forma de abrigo, segurança e afeição. O terceiro, o alimentar, abrangendo desde o oferecimento de um copo d'água ou um pão, mesmo que este 
seja apenas simbólico, a doação do alimento simboliza o ato mais concreto de hospitalidade. Por fim, o quarto ritual, cabendo ao anfitrião entreter o seu convidado ou hóspede. O entretenimento visa propiciar momentos prazerosos às pessoas, seja durante festas, celebrações culturais, jogos e/ou durante as compras que um consumidor faz em determinado estabelecimento do varejo.

A hospitalidade não se restringe apenas a hotéis e restaurantes. Existem diversos serviços que são oferecidos aos clientes que se encontram fora de casa (Powers \& Barrows, 2004; Faria \& Torres, 2015). Para que haja hospitalidade, faz-se necessária a combinação de elementos tangíveis e intangíveis, como os produtos que são oferecidos, os serviços e a atmosfera em que estão inseridos (Lockwood \& Jones, 2004). Na hospitalidade, percebe-se a diferença dos cenários comercial e social (Quadro 1).

Quadro 1 - Comparação entre as hospitalidades social e comercial

\begin{tabular}{|l|l|}
\hline Hospitalidade Social & Hospitalidade Comercial \\
\hline Movida pela oferta & Movida pela demanda \\
\hline Ocasional & Ininterrupta \\
\hline Pequena escala & Grande escala \\
\hline Auto administrada & Administrada por terceiros \\
\hline Instalações não inauguradas & Instalações inauguradas \\
\hline Experiência única & Experiência repetível \\
\hline Atividade personalizada & Economia de escala \\
\hline Experiência social & Experiência de serviço \\
\hline Não visa o lucro & Sustentabilidade financeira \\
\hline
\end{tabular}

Fonte: Adaptado de Lockwood e Jones (2004).

No cenário comercial, incluindo os serviços industriais e públicos (Mullins, 2001), temse o oferecimento da hospitalidade de forma ininterrupta, enquanto o estabelecimento estiver aberto, a experiência do serviço oferecido e o lucro é obtido por meio da operação (Lockwood \& Jones, 2004). Contudo, ela vai além de uma hospitalidade social em grande escala, visto que a experiência comercial permite que os funcionários prestem os serviços desejados pelo cliente e, pelos quais, está disposto a pagar (Lockwood \& Jones, 2004). Chon e Sparrowe (2003) 
esclarecem que a hospitalidade e o turismo podem ser considerados uma grande indústria composta por diferentes serviços como o de alimentos e bebidas, hospedagem, recreação, viagens e de produtos oferecidos como personalizados.

A rede turística e de hospitalidade, segundo Chon e Sparrowe (2003), é dividida em sete grupos: componentes da indústria de alimentos e bebidas; indústria de transportes; componentes do mercado (produto relacionado a outros componentes); viagens e turismo; componentes de recreação, esportes e entretenimento; e componentes do setor de hospedagem e da hospitalidade. Ressalta-se que o setor da hospitalidade abrange toda a experiência que o turista ou consumidor pode ter em diferentes locais, como nos aeroportos, hotéis, restaurantes, dentre outros. Dele fazem parte os prestadores de serviços que estão diretos ou indiretamente inseridos (Figura 1). 
Figura 1 - A rede turística e de hospitalidade

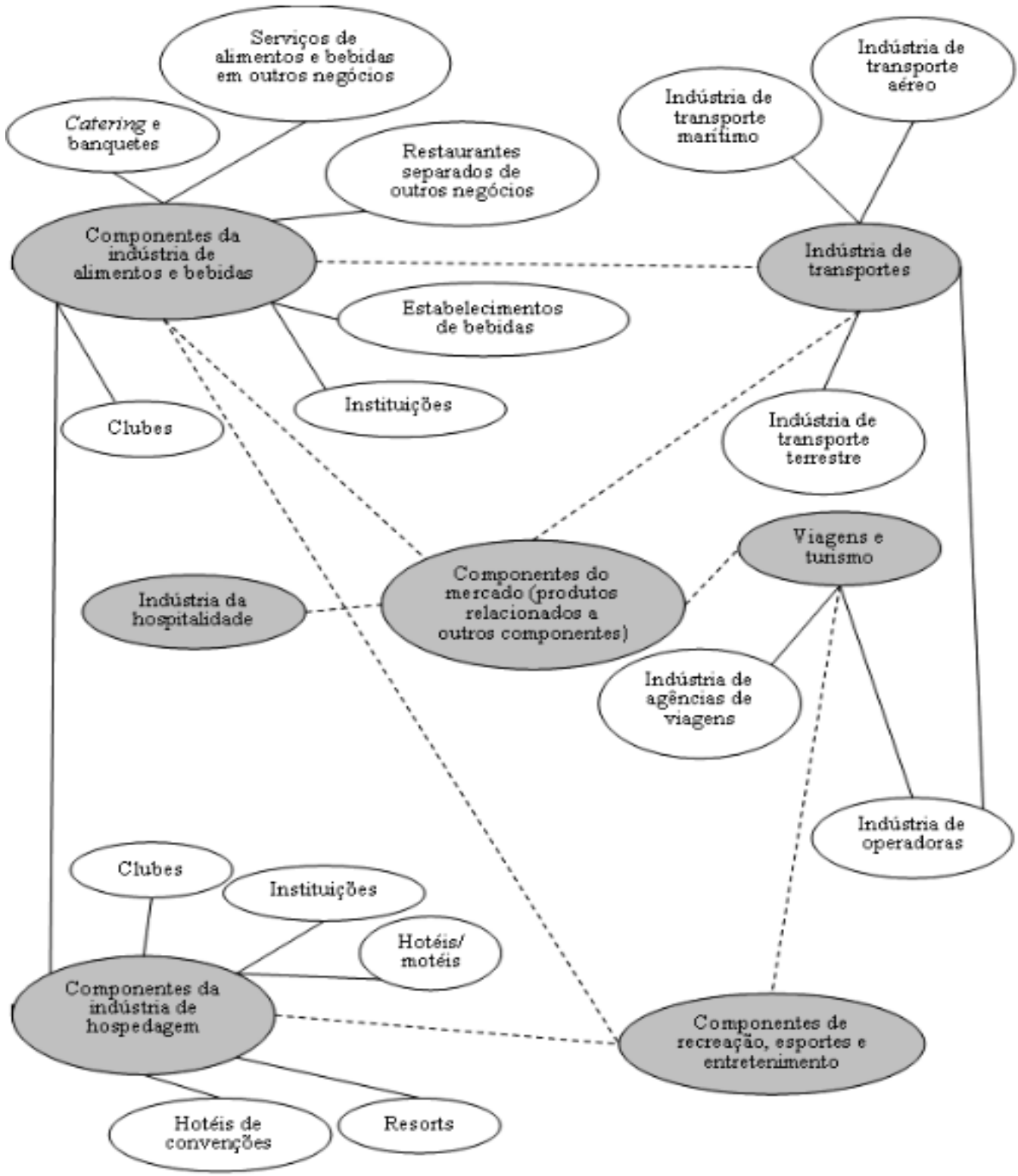

Fonte: Chon e Sparrowe (2003).

\subsection{Hospitableness}

A hospitableness é um componente da hospitalidade manifestado por meio da interação entre provedores e consumidores. Aborda diferentes níveis de necessidade do cliente, fazendo com que este se sinta bem recebido, seguro, amado, respeitado e satisfeito. É o componente que que diferencia a hospitalidade pelo modo como os clientes são tratados (Tasci \& Semrad, 2016). Com base nisso, Telfer (2004) explica que existem diversos elementos relativos à hospitalidade no contexto privado, por exemplo, o espírito da hospitalidade, que tem como características a 
consideração pelo outro, o desejo de agradar, a benevolência, o desejo de satisfazer a necessidade do outro e a obediência aos deveres de acolher. Estes elementos podem ser recíprocos, como a consideração pelo outro, o desejo de ter companhia ou fazer amizade, como também na esperança de que um dia esse gesto seja retribuído. Portanto, pode-se considerar que a pessoa possui características hospitaleiras. Porém, no contexto comercial, o anfitrião não tem condição de escolher quem frequentará o seu estabelecimento e com que frequência isso acontecerá, quais funcionários desempenharão bem as suas atividades ou superarão o esperado e, ainda, se demonstrarão um interesse autêntico pela felicidade do hóspede sem cobrar preços extorsivos pelo hospitalidade (Telfer, 2004).

A hospitableness pode ser entendida como uma virtude moral que, segundo Foot (1978 como citado em Telfer, 2004), é o conjunto de qualidades que um ser humano precisa ter para o seu próprio bem e dos seus semelhantes. São qualidades da vontade e não do intelecto, da circunstância ou do físico e são correlações de certas tendências humanas comuns ao excesso ou à deficiência de motivação. As características hospitaleiras podem ser entendidas como um meio de expressar diversas virtudes, como a benevolência, o zelo pelo bem-estar público e a compaixão. Percebida como uma virtude opcional, todos podem se expressar por ela, mas nem sempre serão hospitaleiros, conforme explicitado por Telfer (2004) e investigado por Marques (2018). No contexto comercial, o anfitrião elege a hospitableness como a principal fonte para demonstrar as virtudes mencionadas. Se esta relação for autêntica e genuína, sobrepondo a outros interesses, esse anfitrião será considerado portador das características hospitaleiras.

Neste estudo, utilizou-se como parâmetro, mas não excludente, o resultado da pesquisa de Asli D. A. Tasci e de Kelly J. Semrad (2016), em que são apresentados 10 itens percebidos na hospitableness, definindo-a como um constructo capaz de gerar uma resposta emocional nos hóspedes embasada nos traços do anfitrião em relação às suas atitudes e ao seu comportamento ao lidar com os clientes. Dentre estes itens constam: os traços da personalidade (ex.: honesto), as atitudes (ex.: cortês) e os comportamentos (ex.: acolhedor).

Os traços de personalidade são categorizados em três componentes de hospitableness (Heartwarming, Heart-assuring e Heartsoothing) e estão interrelacionados de acordo com a pesquisa de Tasci e Semrad (2016, p. 39).

- Componente heartwarming: inclui as atitudes indutoras de emoção - acolhedor, cortês, respeitoso e gentil. 
- Componente heart-assuring: inclui os traços de personalidade que induzem a segurança - confiáveis e honestos.

- Componente heart-soothing: absorve itens reconfortantes ao coração que são os traços de personalidade mais neutros, aqueles que confortam os hóspedes - generosos, sociáveis e abertos (Tasci \& Semrad, 2016; Marques, 2018).

Faz-se necessário compreender que os diversos produtos da hospitalidade podem revelar diferentes perspectivas da hospitableness, por exemplo, como o serviço em um fast food difere do que é praticado em um restaurante sofisticado (Tasci \& Semrad, 2016). Isso, para Chon e Sparrowe (2003, p. 12), influencia na atenção dispensada aos clientes ao mimá-los ou frustrálos, visto que "dedicar mais tempo, fornecer informações adicionais ou demonstrar interesse pelo conforto de um cliente são atitudes do funcionário que deixam esse cliente satisfeito".

\subsection{Servicescape}

O termo servicescape é utilizado para descrever o ambiente físico de uma empresa de serviços. Ele desempenha um papel importante na experiência do serviço, podendo alterar a satisfação dos clientes, principalmente naqueles que possuem alto grau de contato entre as pessoas (Lovelock, Wirtz \& Hemzo, 2011; Reimer \& Khuen, 2005).

$\mathrm{Na}$ literatura existe a discussão a respeito do conceito mais amplo de servicescape em Bitner (1992), Lovelock et al. (2011), Reimer \& Khuen (2005), Nilsson \& Ballantyne (2014), Wakefield \& Blodgett (2016). De outro lado, existem autores que o apresentam como cenário de serviços (Zeithaml, Bitner \& Gremler, 2011), ambiente físico (Kotler, 2000) e atmosfera (Levy \& Weitz, 2000). Na composição desse ambiente está o design interior e exterior, condições do ambiente (temperatura, ruído, odor) e a parte tangível de serviços como o cartão de visitas e materiais de comunicação (Reimer \& Khuen, 2005). Para Lovelock et al. (2011, p. 309), "Servicescape é toda a parte visível do serviço, incluindo decoração, iluminação, aroma, som, arquitetura, vitrine, temperatura e umidade, ambiente etc.".

O ambiente no qual o serviço é montado e o vendedor e o cliente interagem são combinados com as mercadorias tangíveis, facilitando o desempenho e a comunicação (Bernard \& Bitner,1981 como citado em Reimer \& Khuen, 2005). As pessoas interagem entre si e com objetos, interpretando as ações uma das outras. As respostas são baseadas em significados 
atribuídos a ações e interações. $\mathrm{O}$ ambiente físico tem impacto sobre como as pessoas reagem e agem (Blumer, 1962, 1969 como citado em Nilsson \& Ballantyne, 2014). Dessa maneira, o servicescape é um fator importante para formar as impressões de um consumidor sobre um ambiente de serviços. A arquitetura, o design, os funcionários e os clientes que visitam a loja colaboram para formação da imagem da organização, dos produtos e dos serviços (Schuster, Dias \& Battistella, 2016).

O cenário em que a prestação de serviço acontece, é um indicador da qualidade esperada, e ainda influencia na avaliação das dimensões intangíveis, de modo que está diretamente e indiretamente relacionado a qualidade de serviço percebido (Reimer \& Khuen, 2005), pois, o ambiente físico, exerce influência sobre a criação da imagem do consumidor, especialmente nos negócios de serviços como o de uma loja, restaurante ou meios de hospedagens (Zeithaml, Parasuraman \& Berry, 1985; Upadhyaya, El-Shishini, Aziz \& Kumar, 2018).

O cliente, em sua tomada de decisão, busca evidências físicas ou algum indício que seja tangível para aferir a satisfação antes, durante e depois da prestação de serviço. Estes elementos são as instalações físicas da empresa e outras formas de comunicação como sinalização, estacionamento e paisagismo (Zeithaml et al., 2011). Além disso, tem-se as condições ambientais, mesmo que não percebidas conscientemente, elas afetam o bem-estar emocional do cliente, alterando percepções, atitudes e comportamentos. Mediante o emprego dos cinco sentidos, pode-se utilizar as emoções a favor do negócio, estimulando determinados comportamentos por meio de cores, aroma e música (Lovelock et al., 2011). A boa iluminação é uma aliada para destacar produtos, esculpir espaços e capturar o humor ou o sentimento, reforçando a imagem da loja, como também auxilia no disfarce de algumas imperfeições (Levy \& Weitz, 2000).

Levy e Weitz (2000) sustentam que a comunicação visual desempenha um importante papel no ambiente. Além de funcionar como sinalização, ela pode trazer mais informações sobre os produtos e adicionar personalidade e beleza para a loja. Deve-se coordenar sinais e artes gráficas, sendo uma ponte entre a mercadoria e o cliente e facilitando a sua localização no interior da loja. Padronizar a comunicação com um tema auxilia o consumidor em seu deslocamento no interior da loja e no entendimento sobre a proposta do local. Ressalta-se a importância da atualização do material de comunicação, do emprego das informações necessárias e da escrita adequada na apresentação desse sinal. Por fim, alguns elementos teatrais como tecidos, pôsteres e fotografias podem ser utilizados tanto para esconder algo no ambiente 
como para auxiliar na localização de um departamento (Levy \& Weitz, 2000). Para uma loja no varejo, Lovelock et al. (2011) destacam as dimensões e os elementos de projeto:

- Instalações exteriores: estilo arquitetônico, altura, tamanho, cor do edifício, paredes externas e sinalização, fachada, marquise, gramados e jardins, vitrines, entradas, visibilidade, exclusividade, lojas vizinhas, áreas vizinhas, congestionamento, estacionamento e acessibilidade.

- Interior geral: assoalhos e carpetes, esquema de cor, iluminação, aromas, odores, sons e música, acessórios, composição da parede, texturas das paredes (pintura, papel de parede), composição do teto, temperatura, limpeza, largura dos corredores, provadores, elevadores e escadas rolantes, áreas mortas, disposição e apresentação de mercadorias, visibilidade de preços, localização do caixa e tecnologia/modernização.

- Disposição da loja: alocação de espaço para vendas, mercadorias, pessoal e clientes, posicionamento e agrupamento de mercadorias, posicionamento da estação de trabalho, localização de equipamentos, localização do caixa, área de espera, fluxo de tráfego, filas de espera, mobiliário, áreas mortas, localização e arranjos internos dos departamentos.

- Expositores internos: expositores no ponto de venda, pôsteres, placas e cartões, figuras e elementos gráficos, decoração das paredes, ambiente temático, conjunto, estante e caixas, exposição do produto e do preço, caixas de ofertas, latas de lixo e móbiles.

- Dimensões sociais: características pessoais e dos clientes, uniforme dos funcionários, aglomeração, privacidade e autosserviço.

Todos estes elementos mencionados por Lovelock et al. (2011) fazem a composição do ambiente e interferem na percepção que o cliente vai ter sobre a marca, incluindo os funcionários que trabalham no local, os materiais gráficos, elementos visuais e a localização (Figura 2). 
Figura 2 - Elementos de um projeto de um ambiente de varejo

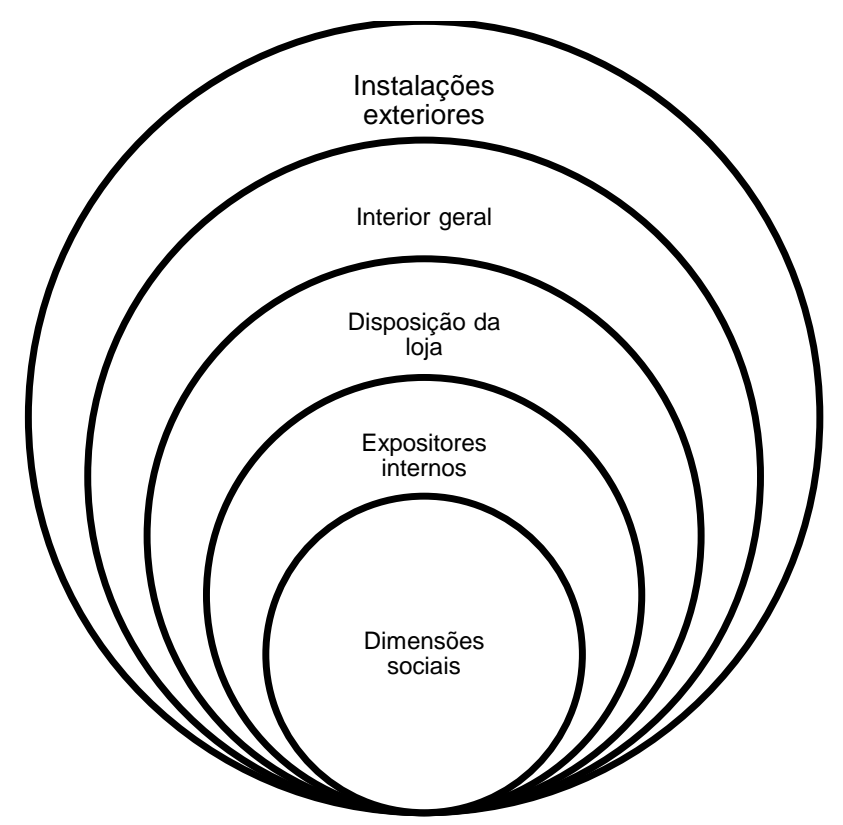

Fonte: Adaptado de Lovelock et al. (2011).

O layout e a sua funcionalidade são aspectos importantes no ambiente físico para a composição do cenário. Ele se refere à disposição dos maquinários, equipamentos e mobília, a forma, tamanho e a relação entre os itens. A funcionalidade relaciona-se com a forma de promover a realização dos objetivos por funcionários e clientes (Zeithaml et al., 2011). Eles percebem o ambiente de forma holística, considerando três dimensões: condição de trabalho; layout do espaço e funcionalidade; e sinais, símbolos e artefatos. Cada dimensão afeta a percepção geral de forma independente e/ou mediante a sua interação com as outras dimensões (Bitner, 1992). Com esta fundamentação, Bitner (1992) elaborou um modelo de compreensão dos relacionamentos entre o ambiente e o usuário de uma organização de serviço (Figura 3). 
Figura 3 - Relacionamentos entre o ambiente e o usuário

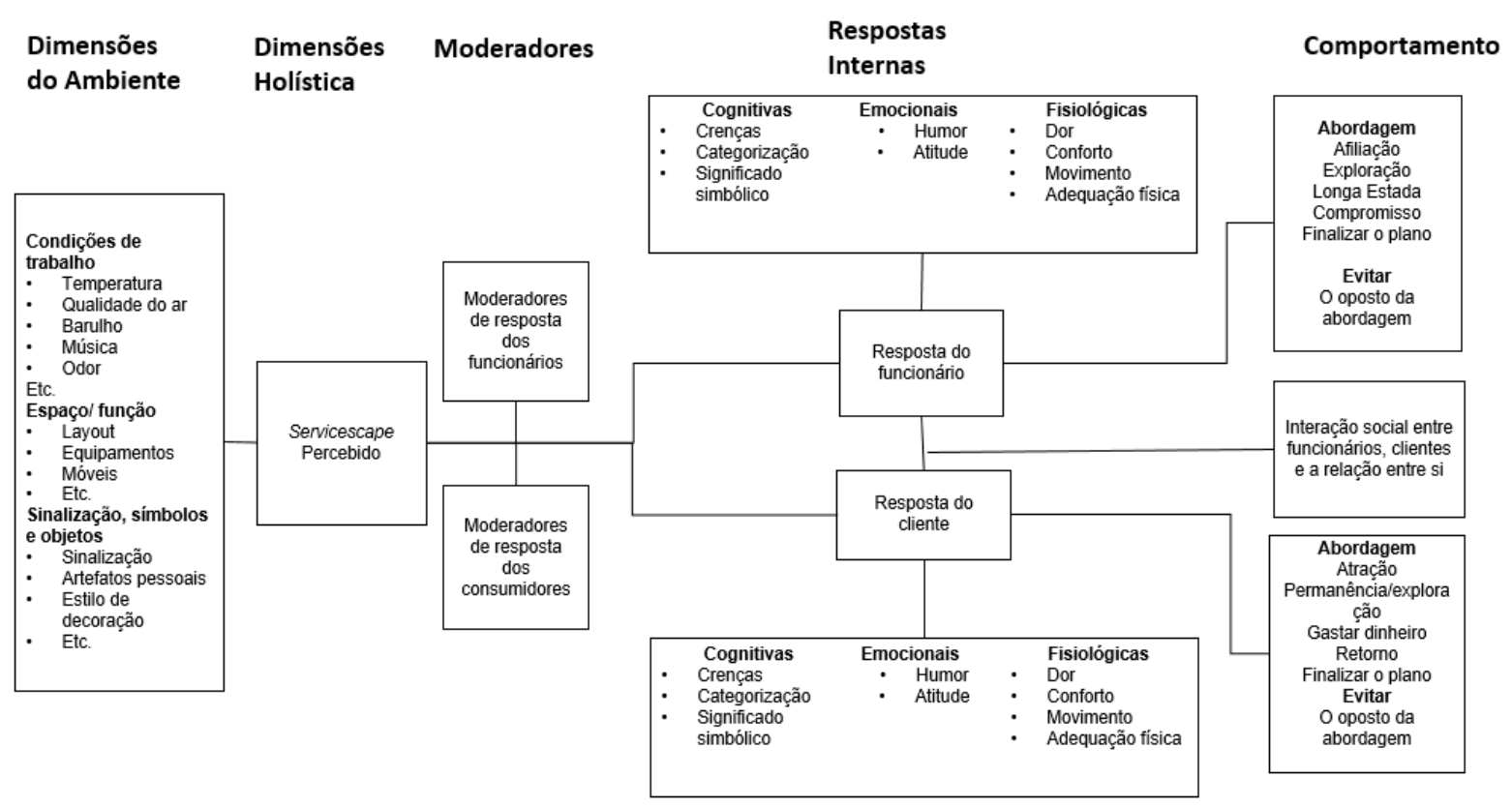

Fonte: Adaptado de Bitner (1992).

Como observado na Figura 3, Bitner (1992) dividiu os relacionamentos entre o ambiente e o usuário em cinco categorias: a) dimensões do ambiente, que envolve as condições físicas do local; b) dimensão holística, que contempla o que é percebido do servicescape naquele ambiente; c) moderadores, para as respostas dos funcionários e dos consumidores; d) respostas internas, relacionadas com as capacidades emocionais, cognitivas e fisiológica dos clientes e dos funcionários; e e) comportamento.

O comportamento humano no servicescape é influenciado pelo ambiente físico. O comportamento individual reage de duas maneiras ao ambiente, por aproximação ou afastamento. Nas interações sociais, o ambiente influencia na qualidade da relação entre clientes e funcionários, especialmente no serviço interpessoal (Bitner, 1992). O autor explica que a tipologia do serviço e o comportamento são influenciados de diversas maneiras pelo ambiente, sendo fundamental identificar quais são aqueles desejáveis pelos clientes e funcionários e como se alinham com as características do ambiente físico.

As respostas internas ao servicescape, de acordo com a psicologia do ambiente, apresentam relações do entorno físico cognitivo, emocional e o fisiológico, essas respostas geradas influenciam o comportamento em determinado ambiente. A percepção do serviço, pode provocar respostas emocionais que influenciam comportamentos. $\mathrm{O}$ ambiente também pode 
Margutti, A. N., Marques, R. B., \& Stefanini C. J. (set./dez. 2020). Hospitableness e servicescape na hospitalidade no contexto do varejo na cidade de São Paulo

provocar reações fisiológicas, como por exemplo, quando há uma música muito alta e o cliente se incomoda (Bitner, 1992).

As respostas internas emitidas pelos funcionários e pelos clientes em determinado ambiente trazem uma nova maneira de como projetá-lo e utilizar o servicescape para causar um impacto positivo (Bitner, 1992). De acordo com Lovelock et al. (2011), o projeto do ambiente físico e a maneira como os funcionários interagem no local permitem a criação da identidade corporativa e a modelagem da natureza de experiência do cliente. Isso, porque os estímulos ambientais são processados pelos cinco sentidos - visão, audição, paladar, tato e olfato -, que identificam as sensações. A partir delas, os processos cognitivos e psicológicos criam conhecimentos, sentimentos ou afeições sobre o ambiente e, assim, as emoções levam a uma sensação de aproximação ou de afastamento (Figura 4) (Lovelock et al., 2011). Na literatura da hospitalidade, a aproximação se estabelece em um contexto hospitaleiro e o afastamento em um cenário hostil (Alves \& Marques, 2019).

Figura 4: Sensações, sentimentos e emoções

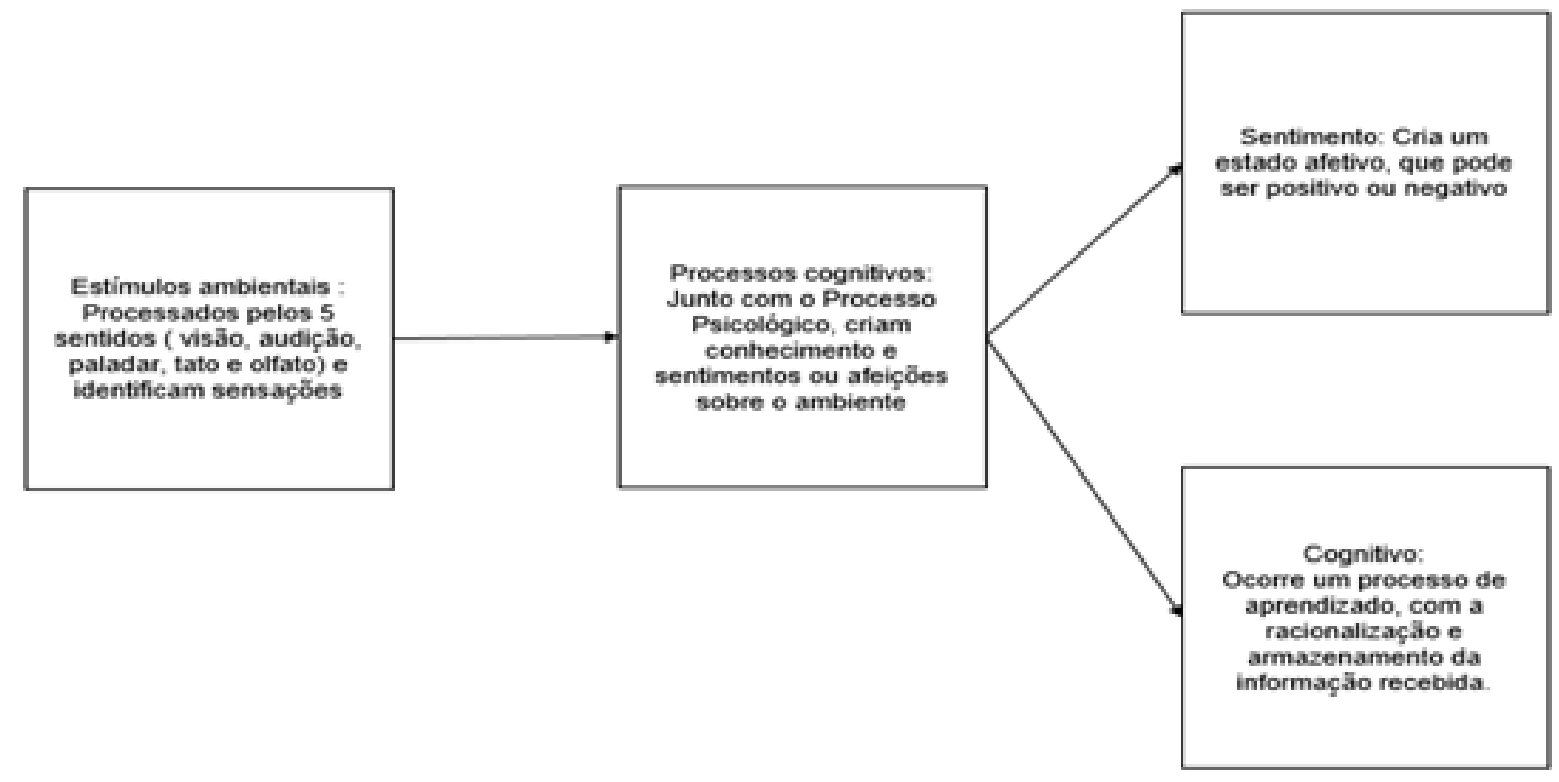

Fonte: Adaptado de Lovelock et al. (2011).

Na perspectiva de marketing e criação de valor, ambientes de diferentes tipos como hotéis, restaurantes e lojas, objetos de estudo desta pesquisa, além de hospitais e parques temáticos, são locais que podem ter um ambiente onde qualquer cliente se sinta à vontade e muito satisfeito (Lovelock et al., 2011). Para tanto, com a finalidade de tomar decisões 
referentes a um cenário de serviços, faz-se necessária uma visão multidisciplinar entre todos os setores envolvidos, para que a imagem da empresa esteja alinhada com as instalações e, no final, flua durante a operação conforme o planejado (Zeithaml et al., 2011).

\section{Varejo}

O varejo é o conjunto de atividades de negócios referente à venda de bens e serviços por meio da comercialização a consumidores finais, tanto para a utilização pessoal como para a familiar (Kotler, 2000; Levy \& Weitz, 2000; Mattar, 2011; Parente, 2000). Além disso, entendese também como processo o de compra de produtos em grande escala dos produtores atacadistas e a venda em menor quantidade para o consumidor final (Richter, 1954 como citado em Las Casas, 2004). Constitui-se em uma relação que acontece entre uma pessoa física e uma pessoa jurídica (Sociedade Brasileira de Varejo e Consumo, 2019), estando incluso o desafio de adicionar valor e entregar experiências memoráveis ao consumidor. Como há o contato mais estreito, principalmente em ambientes físicos, permite ao consumidor tocar, cheirar e criar a sua percepção sobre a marca e o produto, independente da aquisição ou não ao final (Las Casas, 2004; Mattar, 2011; Mulhern, 1997; Rocha, 2018).

Esta prestação de serviço não acontece apenas em lojas físicas. $\mathrm{O}$ varejo possui diferentes canais como a venda direta, por catálogo, via internet, telefone e ambulantes, entre outros formatos (Mattar, 2011; Parente, 2000). O varejista é representado por aquele que intermedia a distribuição entre o produtor e o cliente, sendo definido como o conjunto de distribuição e de atividades de criação de valor, Em geral, é realizada pelo dono da marca para vender e distribuir os produtos ou serviços para uso próprio ou de um familiar (Prasad \& Seshanna, 2015).

A fim de aumentar o valor do produto os varejistas devem fornecer uma variedade de produtos e serviços, dividir grandes lotes em pequenas quantidades e possuir estoque, além de oferecer o crédito para compras e amostras para que o consumidor possa conhecer antes de comprar (Levy \& Weitz, 2000). Ressalta-se que o atacadista é responsável pela compra do produto dos fabricantes e a revenda aos varejistas. Ao varejista, cabe a revenda do produto ao cliente final. Muitos atacadistas também são varejistas ao venderem o produto para o consumidor final e, atacadista, quando vendem ao dono do restaurante, porém, não são considerados como varejo, por não ser esta a sua maior fonte de receita (Levy \& Weitz, 2000; Parente, 2000). Como varejista, pode apresentar diferentes tipos e formatos de negócios que 
Margutti, A. N., Marques, R. B., \& Stefanini C. J. (set./dez. 2020). Hospitableness e servicescape na hospitalidade no contexto do varejo na cidade de São Paulo

seguem alguns critérios: mercadoria comercializada; propriedade/filiação/contratação; tamanho; localização; nível de serviço; forma legal de constituição; características de organização; e canal de venda utilizado (Mattar, 2011).

Mattar (2011) ensina que as lojas de conveniência surgiram em 1940, em lugares mais movimentados e com horários flexíveis para atender as pequenas compras emergenciais por parte dos consumidores. Além de pequenas, apresentam por característica o autosserviço. Temse também o shopping center, que é um modelo desenvolvido desde a antiguidade, sido utilizado no Grande Bazaar de Isfahan, no Irã, no século X a.C., na Oxford Covered Market, na Inglaterra, em 1774 , nos Estados Unidos em Rhode Island, em 1828 e, em Paris, na Galleria Vittorio Emanuelle II, na década de 1860. Na década 1950, houve o adensamento populacional em grandes conjuntos habitacionais suburbanos. Buscando atender às necessidades de compra desse mercado, muitos shopping centers foram construídos. Posteriormente, em 1956, nos Estados Unidos, esse modelo de varejo passou a ser fechado e voltado para o interior, devido ao inverno rigoroso. Este conceito ficou popularmente conhecido como shopping mall (Mattar, 2011).

Parente (2000) classifica as instituições de varejo por tipo de propriedade: a) independente, que possui apenas uma loja; b) redes, que operam mais de uma loja sob a mesma direção; c) franquias, que é uma maneira de os varejistas expandirem, permitindo que o empresário conduza o negócio de acordo com o padrão e procedimentos da marca; e d) departamento alugados, que estão alocados dentro de uma loja de varejo, mas são gerenciados por outra empresa, geralmente, requerem alto grau de especialização no negócio. Com a inserção do varejo, tem-se a uma classificação que se inicia no nível dois, no qual o fabricante efetua a venda diretamente ao consumidor. A partir do nível três, surge o varejista como intermediador que, neste caso, pode ser considerado venda direta. No nível quatro, aparecem dois intermediários, sendo atacadistas e varejistas intermediários. Para os bens de consumo, vários canais são utilizados para a distribuição de seus produtos (Parente, 2000). Tem-se ainda a abordagem macro da Sociedade Brasileira de Varejo e Comércio (2019), dividida em três grandes grupos de varejo: varejo de bens de consumo em geral; varejo de carros e combustíveis; e varejo de serviço.

A tecnologia aliada à inovação trouxe uma nova forma de criar diferenciais para os estabelecimentos como a venda on-line. Em um ambiente físico, a atmosfera que é criada por meio da comunicação visual, iluminação, cores, música e aromas estimulam a percepção dos 
clientes e pode afetar o comportamento de compra. No setor de serviços, estes pontos são diferenciais entre os concorrentes (Levy \& Weitz, 2000). A venda de serviço é presente no varejo, como por exemplo, a estada em um hotel e de entrega de alimentação. Para que estes serviços sejam entregues nem sempre acontecem em lojas, pois têm como aliados a tecnologia virtual. $\mathrm{O}$ atendimento e os serviços prestados ao consumidor fazem parte de um relacionamento que é construído entre o varejista e o cliente. Quando esta relação acontece de maneira adequada, tende a ser duradoura, gerando a fidelização desse consumidor. A qualidade da relação estabelecida nesse contato é um importante diferencial para o negócio (Parente, 2000), pois, é nesse tipo de interação anfitrião-cliente que está circunscrita a hospitalidade no varejo (Faria \& Torres, 2015). A forte concorrência no setor facilita o surgimento das imitações em serviços e a disputa pelo cliente, o que estimula a elevação da qualidade do serviço prestado e, assim, ganhar a preferência deste consumidor (Parente, 2000).

Las Casas (2004) defini serviço como atos ou ações realizadas por empresas ou indivíduos, em que alguns estão ligados à transferência de um bem, como a locação de um imóvel, enquanto outros, como os de advocacia, que são efetivados por meio da utilização de conhecimentos técnicos sobre a área. Os serviços oferecidos no varejo devem facilitar ao consumidor todo o processo de compra, como a busca por um produto, a comparação, a seleção e, por fim, a compra (Parente, 2000). A partir desta definição, Las Casas (2004) classifica os serviços em tangíveis e intangíveis, qualificando o primeiro como sendo algum bem que pode ser armazenado e transportado, por exemplo, a compra de um carro, computador, televisão, etc. O serviço intangível é aquele que não pode ser tocado, transportado ou armazenado, como o corte de cabelo, fazer as unhas, uma música agradável, um cheiro que emane no ar no ato da compra. Assim, as diferenças do varejo de serviço estão na ênfase em que é colocado na prestação de serviço, e não na mercadoria que é vendida. Os restaurantes, por exemplo, oferecem o alimento, mas também o serviço do garçom, a música e um ambiente agradável (Levy \& Weitz, 2000).

Las Casas (2004) explica que são considerados serviços de consumo aqueles prestados diretamente ao consumidor:

- Conveniência: o consumidor não tem tempo a perder procurando empresas que prestam serviços, visto que as diferenças não podem ser percebidas.

- Escolha: de acordo com o serviço prestado e a história das empresas. O custo é 
diferente e, dessa forma, cabe ao consumidor decidir.

- Especialidade: serviço especializado, pelo qual o consumidor tem que procurar para obter o melhor. Destaca-se que, neste caso, ele pode se apresentar como básico ou até o completo com o intuito de atender a demanda.

De acordo com Zeithaml et al. (1985), as quatro principais características que distinguem o varejo de serviço são: a) Intangibilidade, cujo serviço não pode ser estocado ou protegido, dificuldade em comunicar e de precificar; b) inseparabilidade, os consumidores estão envolvidos, sendo difícil massificar sua produção; c) heterogeneidade, padrão e controle de qualidade são difíceis de atingir; e d) ser perecível, o serviço não pode ser estocado.

Para a regulamentação de serviços no Brasil, a Sociedade Brasileira de Varejo e Consumo (2019) possui a Classificação Nacional de Atividades Econômicas (CNAE), que é um instrumento de padronização nacional dos códigos das atividades econômicas, utilizados pelos diversos órgãos da Administração Tributária do Brasil e adotada pelo Sistema Estatístico Nacional e órgãos de administração federal.

\section{Materiais e métodos}

Neste artigo, foi realizada uma pesquisa de caráter exploratório, com métodos quantitativos a partir das escalas testadas em Hospitalidade de Blain e Lashley (2014), Hospitableness de Tasci e Semrad (2016) e Servicescape de Choi, Lee e Seo (2018). As escalas de medida foram desenvolvidas baseadas no modelo conceitual da revisão da literatura. Para a escala de Servicescape (Choi et al., 2018), utilizou-se o fator 1, referente a atmosfera de compra, sendo que as perguntas relacionadas à cidade em que estão inseridas foram excluídas. A escala de Hospitalidade (Blain \& Lashley, 2014) foi traduzida e aplicada no seu formato padrão, enquanto que a escala de Hospitableness (Tasci \& Semrad, 2016) recebeu explicações aos significados das palavras com o objetivo de melhorar o entendimento e compreensão dos respondentes.

Os itens constantes nas escalas foram medidos utilizando a escala Likert de sete pontos, sendo (1) descordo totalmente e (7) concordo totalmente. A primeira seção do questionário foi constituída com 10 itens a respeito da cultura de hospitalidade da empresa do respondente pela perspectiva do cliente/visitante. A escala foi desenvolvida utilizando múltiplos itens de três fontes diferentes: Blain e Lashley (2014) com uma abordagem sobre a percepção do cliente em 
relação ao anfitrião; Tasci e Semrad (2016) que, por intermédio de palavras, remete a sensação de hospitableness; e Choi et al. (2018) com enfoque na atmosfera de compra. A última seção do questionário traz as informações sociodemográficas (idade, sexo, nível de educação, renda, estado civil e ocupação).

A seleção da amostra foi por conveniência e pela técnica Bola de neve, não probabilística, aplicada aos frequentadores de estabelecimentos de varejo (hospedagem, alimentação e lojas) da cidade de São Paulo, alcançando 105 respondentes.

A análise quantitativa foi realizada utilizando a técnica proposta de modelagem de equações estruturais que, de acordo com Hair et al. (2009), explica as relações entre as múltiplas variáveis, examinando a estrutura de inter-relações entre uma série de equações que descrevem as relações entre os constructos (dimensões, indicadores).

Por hipóteses de pesquisa, tem-se:

H1: O Servicescape (ambiente físico) impacta na percepção de Hospitalidade do cliente. H2: As características hospitaleiras (Hospitableness) influenciam na percepção de Servicescape (ambiente físico).

H3: As características hospitaleiras (Hospitableness) estão diretamente relacionadas a percepção de Hospitalidade do cliente.

O modelo teórico proposto para este estudo indica que a Hospitableness influencia a Hospitalidade e o Servicescape, assim como o Servicescape é influenciado pela Hospitableness que influencia a hospitalidade (Figura 5). 
Figura 5 - Modelo estrutural proposto com base na teoria

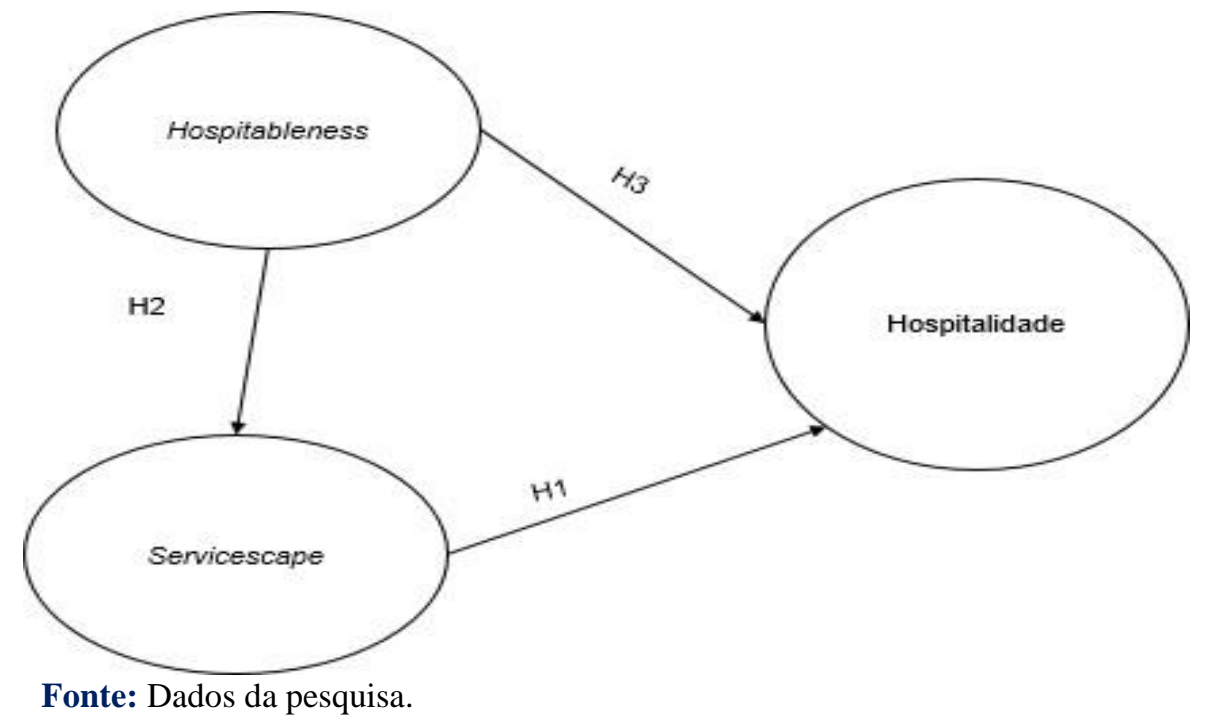

O instrumento de coleta de dados para esta pesquisa foi um questionário (Vergara, 2005) disponibilizado no Google Forms, entre os meses de janeiro a abril de 2019. O questionário foi testado e validado por pesquisadores e acadêmicos da Hospitalidade.

O software utilizado para a modelagem da equação estrutural com PLS foi o SMARTPLS 3. Os dados obtidos foram inseridos no software utilizando uma planilha de Excel. Nesta planilha, cada pergunta foi identificada com siglas referentes ao seu constructo e os valores numéricos foram preenchidos. As variáveis utilizadas na pesquisa para Servicescape (Choi et al., 2018) podem ser verificadas no Quadro 2. 
Quadro 2 - Constructos de Servicescape

\begin{tabular}{|l|l|}
\hline \multicolumn{1}{|c|}{ SER VICESCAPE} & Constructo \\
\hline A temperatura do local é confortável. & SCP01 \\
\hline O local é limpo e organizado. & SCP02 \\
\hline A iluminação no ambiente é adequada. & SCP03 \\
\hline O barulho dentro do estabelecimento é aceitável. & SCP04 \\
\hline Os funcionários estão sempre arrumados. & SCP05 \\
\hline $\begin{array}{l}\text { O uso de cores na decoração do local gera um } \\
\text { ambiente empolgante. }\end{array}$ & SCP06 \\
\hline $\begin{array}{l}\text { A informação sobre o produto está disponível no } \\
\text { local. }\end{array}$ & SCP07 \\
\hline $\begin{array}{l}\text { No geral, o layout do estabelecimento facilita a } \\
\text { locomoção. }\end{array}$ & SCP08 \\
\hline Os funcionários têm uma boa atitude em servir. & SCP09 \\
\hline A arquitetura do local possui um caráter atrativo. & SCP10 \\
\hline O interior é decorado com uma moda atrativa. & SCP11 \\
\hline No geral, o design do estabelecimento é interessante. & SCP12 \\
\hline As informações pré-compras estavam disponíveis. & SCP13 \\
\hline
\end{tabular}

Fonte: Choi et al., 2018.

As afirmativas utilizadas como base para Hospitableness (Tasci \& Semrad, 2016) podem ser observadas no Quadro 3: 
Margutti, A. N., Marques, R. B., \& Stefanini C. J. (set./dez. 2020). Hospitableness e servicescape na hospitalidade no contexto do varejo na cidade de São Paulo

Quadro 3 - Constructos para Hospitableness

\begin{tabular}{|c|c|}
\hline HOSPITABLENESS & Constructo \\
\hline Gentileza & HBS01 \\
\hline Educação & HBSO2 \\
\hline Felicidade & HBS03 \\
\hline Honestidade & HBS04 \\
\hline Presteza & HBS05 \\
\hline Sinceridade & HBS06 \\
\hline Flexibilidade & HBS07 \\
\hline Amizade & HBS08 \\
\hline Confiança & HBS09 \\
\hline Atenção & HBS10 \\
\hline Generosidade & HBS11 \\
\hline Cortesia & HBS12 \\
\hline Consistência & HBS13 \\
\hline Respeito & HBS14 \\
\hline Acolhimento & HBS15 \\
\hline Personalização & HBS16 \\
\hline Digno de confiança & HBS17 \\
\hline Profissional & HBS18 \\
\hline Atencioso & HBS19 \\
\hline Mente aberta & HBS20 \\
\hline Bem preparado & HBS21 \\
\hline Acomodação & HBS22 \\
\hline Dedicado ao serviço & HBS23 \\
\hline
\end{tabular}

Fonte: Tasci e Semrad (2016).

Para hospitalidade (Blain \& Lashley, 2014), foram utilizadas as seguintes afirmativas (Quadro 4): 
Quadro 4 - Constructos para Hospitalidade

\begin{tabular}{|c|c|}
\hline HOSPITALIDADE & Constructo \\
\hline $\begin{array}{l}\text { Eu sinto que os colaboradores do local onde visitei } \\
\text { colocam a minha satisfação antes da deles. }\end{array}$ & HOSP01 \\
\hline $\begin{array}{l}\text { Percebo que os funcionários fazem de tudo para que } \\
\text { eu tenha um excelente momento durante o período } \\
\text { em que sou atendido. }\end{array}$ & HOSP02 \\
\hline $\begin{array}{l}\text { Consigo notar que os funcionários sempre têm em } \\
\text { mente a vontade de fazer com que eu me sinta bem } \\
\text { acolhido. }\end{array}$ & HOSP03 \\
\hline $\begin{array}{l}\text { Eu sinto que o conforto dos clientes é o mais } \\
\text { importante para os funcionários. }\end{array}$ & HOSP04 \\
\hline $\begin{array}{l}\text { Observo uma satisfação genuína nos funcionários em } \\
\text { fazer com que eu me sinta especial. }\end{array}$ & HOSP05 \\
\hline $\begin{array}{l}\text { Percebo que os funcionários gostam de assumir } \\
\text { responsabilidade pelo meu bem-estar. }\end{array}$ & HOSP06 \\
\hline $\begin{array}{l}\text { Consigo notar que significa muito para o funcionário } \\
\text { quando eu demonstro a aprovação pela hospitalidade } \\
\text { dele. }\end{array}$ & HOSP07 \\
\hline $\begin{array}{l}\text { Eu sinto que é importante para o funcionário fazer as } \\
\text { coisas que eu espero durante todo o período em } \\
\text { presta serviço. }\end{array}$ & HOSP08 \\
\hline $\begin{array}{l}\text { Percebo que os funcionários procuram oportunidades } \\
\text { para me ajudar. }\end{array}$ & HOSP09 \\
\hline $\begin{array}{l}\text { Me sinto único no momento em que os funcionários } \\
\text { prestam serviço. }\end{array}$ & HOSP10 \\
\hline $\begin{array}{l}\text { Os funcionários tentam estar na mesma sintonia de } \\
\text { comunicação em que eu estou. }\end{array}$ & HOSP11 \\
\hline Sinto atenção a qualquer momento. & HOSP12 \\
\hline $\begin{array}{l}\text { Percebo que para os funcionários, é motivador } \\
\text { assumir a responsabilidade pelo bem-estar de outras } \\
\text { pessoas. }\end{array}$ & HOSP13 \\
\hline
\end{tabular}

Fonte: Blain e Lashley, 2014. 
Algumas perguntas não apresentaram carga suficiente nas respostas e tiveram que ser excluídas do estudo, foram elas: Hospitableness - HBS01, HNS02, HBS03, HBS06, HBS07, HBS09, HBS11, HBS12, HBS14, HBS 16, HBS17, HBS18, HBS19, HBS20 e HBS23. Em Hospitalidade foram: HOSP02, HOSP03, HOPS04, HOPS05, HOP06, HOP10, HOP12 e HOP13 e, por fim, em Servicescape foram desconsideradas as variáveis SCP01, SCP02, SCP03, SCP05, SCP07, SCP10, SCP12 e SCP13. O modelo para esta pesquisa foi ajustado e os novos valores foram analisados para a sua conclusão.

\section{Resultados e discussão}

A partir dos dados obtidos na pesquisa de campo, composta por 105 respondentes, confirmou-se que a amostra é: predominantemente feminina (68,57\%); com idade superior a 40 anos (43,81\%); e com renda superior a $\mathrm{R} \$ 4.400,00$ (72,12\%). Em relação ao estado civil, os respondentes apresentaram um comportamento equilibrado entre casados $(53,33 \%)$ e solteiros $(39,05 \%)$. Com ocupação formal obteve-se 48,57\% e, escolaridade em pós-graduação, $56,73 \%$. Contudo, pode-se afirmar que nesta pesquisa o principal grupo respondente foi o feminino, adulto, com escolaridade e renda elevadas (Tabela 1). 
Tabela 1 - Estatística descritiva

\begin{tabular}{|c|c|c|c|}
\hline & & $\begin{array}{l}\text { Frequência } \\
(\mathrm{n}=105)\end{array}$ & $\%$ \\
\hline \multirow[t]{4}{*}{ Faixa Etária } & Entre 18 e 25 anos & 8 & $7,62 \%$ \\
\hline & Entre 26 e 29 anos & 20 & $19,05 \%$ \\
\hline & Entre 30 e 40 anos & 31 & $29,52 \%$ \\
\hline & Acima de 40 anos & 46 & $43,81 \%$ \\
\hline \multirow[t]{2}{*}{ Gênero } & Feminino & 72 & $68,57 \%$ \\
\hline & Masculino & 33 & $31,43 \%$ \\
\hline \multirow[t]{7}{*}{ Renda Mensal } & Até $\mathrm{R} \$ 880,00$ & 4 & $3,85 \%$ \\
\hline & $\begin{array}{l}\text { Entre } \mathrm{R} \$ 880,00 \mathrm{e} \\
\mathrm{R} \$ 2.640,00\end{array}$ & 5 & $4,81 \%$ \\
\hline & Entre $\mathrm{R} \$ 2640,00 \mathrm{e}$ & 20 & $19,23 \%$ \\
\hline & $\mathrm{R} \$ 4.400,00$ & & \\
\hline & Entre $\mathrm{R} \$ 4.400,00 \mathrm{e}$ & 36 & $34,62 \%$ \\
\hline & $\mathrm{R} \$ 8.800,00$ & & \\
\hline & Acima de $\mathrm{R} \$ 8.800,00$ & 39 & $\mathbf{3 7 , 5 0 \%}$ \\
\hline \multirow[t]{4}{*}{ Estado Civil } & Casado & 56 & $53,33 \%$ \\
\hline & Separado & 6 & $5,71 \%$ \\
\hline & Solteiro & 41 & $39,05 \%$ \\
\hline & Viúvo & 2 & $1,90 \%$ \\
\hline \multirow[t]{4}{*}{ Ocupação } & Autônomo & 21 & $20,00 \%$ \\
\hline & Empregado formal & 51 & $48,57 \%$ \\
\hline & Funcionário público & 18 & $17,14 \%$ \\
\hline & Não trabalho & 15 & $14,29 \%$ \\
\hline \multirow[t]{4}{*}{ Escolaridade } & Ensino fundamental & 1 & $0,96 \%$ \\
\hline & Ensino Médio & 5 & $4,81 \%$ \\
\hline & Ensino Superior & 39 & $\mathbf{3 7 , 5 0 \%}$ \\
\hline & Pós-graduação & 59 & $56,73 \%$ \\
\hline
\end{tabular}

Fonte: Dados da pesquisa.

Em relação aos estabelecimentos avaliados, 67,96\% dos respondentes desta pesquisa avaliaram estabelecimentos de alimentação, conforme apresenta a Tabela 2. 
Tabela 2 - Divisão por tipos de estabelecimentos

\begin{tabular}{lcc}
\hline Tipos de estabelecimentos & $\begin{array}{c}\text { Frequência } \\
(\mathbf{n = 1 0 5})\end{array}$ & $\%$ \\
\hline Alimentação & 70 & $\mathbf{6 7 , 9 6 \%}$ \\
Loja & 16 & $\mathbf{1 5 , 5 3 \%}$ \\
Meio de hospedagem & 19 & $\mathbf{1 8 , 4 5 \%}$ \\
\hline Total & $\mathbf{1 0 5}$ & $\mathbf{1 0 0 \%}$ \\
\hline
\end{tabular}

Fonte: Dados da pesquisa.

A elaboração da modelagem por equações estruturais, inicialmente, pressupõe a verificação da validade dos constructos. Os indicadores de confiabilidade e validade empregados neste estudo foram o Alfa de Croncach, confiabilidade composta e variância média extraída (AVE). O Alfa de Cronbach (AC) é uma medida de confiabilidade e aceitabilidade dos constructos (Hair, Black, Babin \& Anderson, 2010; Stefanini et al., 2018). Neste estudo, adotou-se como critério de aceitação o mínimo 0,70. Os constructos apresentaram aceitabilidade a partir de resultados significativos, como: Hospitableness $(0,925)$, Hospitalidade $(0,906)$ e Servicescape $(0,927)$.

A variância média extraída (AVE) mensura, por meio de um percentual médio de variação, a convergência em um conjunto de itens que formam o constructo (Hair et al, 2010; Stefanini et al., 2018). O critério adotado para análise é que ele seja $>0,50$. Os resultados dos constructos desta pesquisa apresentaram os seguintes resultados: Hospitableness $(0,656)$, Hospitalidade $(0,727)$ e Servicescape $(0,774)$. Portanto, todos os constructos têm validade convergente adequada. Na sequência, os resultados da confiabilidade composta, que é uma medida da confiabilidade geral de uma coleção de itens heterogêneos, mas semelhantes (Hair et al, 2010; Stefanini et al., 2018) e que deve ser >0,70: Hospitableness $(0,938)$, Hospitalidade $(0,930)$ e Servicescape $(0,945)$. Estes valores confirmam a confiabilidade geral do modelo. 
Margutti, A. N., Marques, R. B., \& Stefanini C. J. (set./dez. 2020). Hospitableness e servicescape na hospitalidade no contexto do varejo na cidade de São Paulo

Tabela 3 - Alfa de Cronbach, Confiabilidade Composta e AVE

\begin{tabular}{lcccc}
\hline \multicolumn{1}{c}{$\begin{array}{c}\text { Construct } \\
\text { (Dimension/Indicador) }\end{array}$} & Loading & $\begin{array}{c}\text { Alfade } \\
\text { Cronbach }\end{array}$ & $\begin{array}{c}\text { Composite } \\
\text { Reliability (CR) }\end{array}$ & $\begin{array}{c}\text { Average } \\
\text { Variance } \\
\text { Extracted } \\
\text { (AVE) }\end{array}$ \\
\hline Hospitableness & 0,793 & 0,925 & 0,938 & 0,656 \\
\hline HBS04 & 0,852 & & \\
HBS05 & 0,793 & & \\
HBS08 & 0,821 & & \\
HBS10 & 0,783 & & & \\
HBS13 & 0,828 & & & \\
HBS15 & 0,875 & & & \\
HBS21 & 0,724 & & & \\
HBS22 & & 0,906 & & \\
\hline Hospitalidade & 0,842 & & & \\
\hline HOSP01 & 0,853 & & \\
HOSP07 & 0,825 & & \\
HOSP08 & 0,865 & & \\
HOSP09 & 0,877 & & \\
HOSP11 & 0,879 & & \\
\hline Servicescape & 0,863 & & \\
\hline SCP04 & 0,893 & & \\
SCP06 & 0,897 & & \\
SCP08 & 0,865 & & \\
SCP09 & & & \\
SCP11 & & & \\
\hline
\end{tabular}

Fonte: Dados da pesquisa.

A relação estabelecida entre os constructos auxilia na medição do equilíbrio do modelo, por meio de uma análise de interdependência entre eles. Identifica se, individualmente, cada constructo mede aquilo que se propôs, sem se confundir com os demais. Esta medida é a validade discriminante e o melhor critério para averiguação é o Fornell- Larcker (Hair et. al, 2009; Moretti \& Pinotti, 2018). Pode-se afirmar que as variáveis latentes foram comprovadas de forma significativa neste estudo (Tabela 4). 
Margutti, A. N., Marques, R. B., \& Stefanini C. J. (set./dez. 2020). Hospitableness e servicescape na hospitalidade no contexto do varejo na cidade de São Paulo

Tabela 4 - Validade discriminante dos constructos pelo critério de Fornell - Larcker

\begin{tabular}{lrrr}
\hline & Hospitableness & Hospitalidade & Servicescape \\
\hline Hospitableness & 0,810 & & \\
Hospitalidade & 0,799 & 0,853 & \\
Servicescape & 0,800 & 0,789 & 0,880 \\
\hline
\end{tabular}

Fonte: Dados da pesquisa.

O coeficiente de caminho (T) indica o quanto as hipóteses do estudo podem ser aceitas ou rejeitadas. A variação de valores é de +1 a -1 , valores próximos a +1 indicam relações positivas fortes entre os constructos e, ao contrário, significa relações fracas. Desta maneira, todas as hipóteses consideradas neste estudo foram aceitas (Figura 6).

Figura 6 - Resultado geral do modelo, com coeficiente de caminho (T)

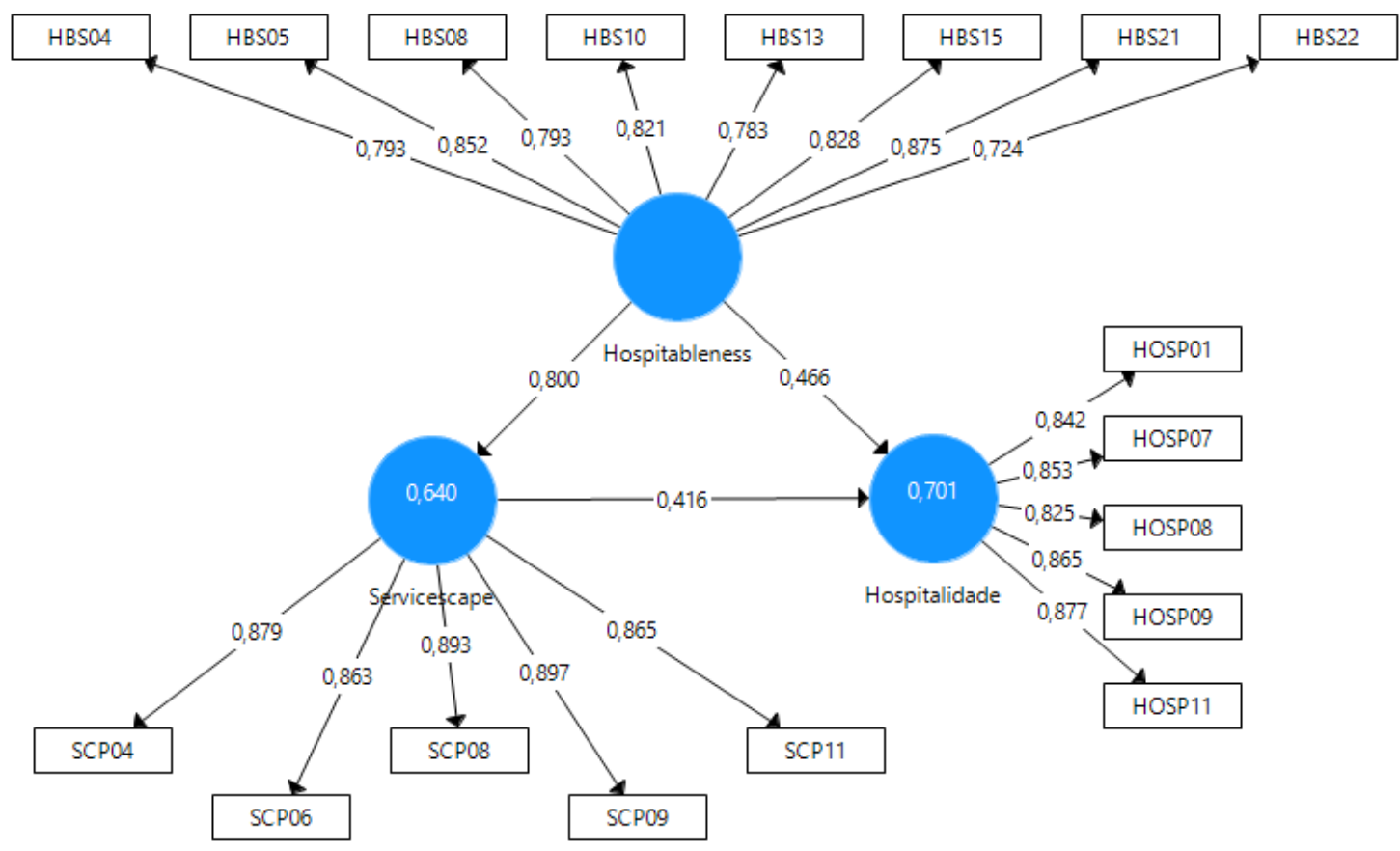

Fonte: Dados da pesquisa.

A utilização do software SmartPLS permite avaliar a relação entre os constructos e testar a sua significância (Hair et. al, 2009; Moretti \& Pinotti, 2018). Para isso, utilizou-se o recurso bootstrapping para medir os valores do Teste T de Student que, neste estudo, o nível de confiança obteve p-valor de $10 \%$, sendo que, para a relação entre Hospitableness e Hospitalidade e Hospitableness e Servicescape, o valor de confiança ficou a 5\%. 
Margutti, A. N., Marques, R. B., \& Stefanini C. J. (set./dez. 2020). Hospitableness e servicescape na hospitalidade no contexto do varejo na cidade de São Paulo

Tabela 5 - Avaliação do modelo estrutural hipotético (Test T e P Value)

\begin{tabular}{lccc}
\hline & T & P valor & Hipóteses \\
\hline H1: Servicescape -> Hospitalidade & 3,247 & 0,001 & Suportada \\
H2: Hospitableness $->$ Servicescape & 18,174 & 0,000 & Suportada \\
H3: Hospitableness $->$ Hospitalidade & 3,746 & 0,000 & Suportada \\
\hline
\end{tabular}

Fonte: Dados da pesquisa.

A primeira hipótese $\mathrm{H} 1$ (O ambiente físico impacta na percepção de Hospitalidade do cliente) foi suportada conforme apresentada na Tabela 5. Assim, considerou-se que o respondente associa o ambiente físico à percepção de hospitalidade característicos dos espaços comerciais que buscam harmonizar seu espaço/ambiente para causar a sensação de ser bem recebido. Esta assertiva aproxima-se das discussões de Camargo (2004) e Lashley (2004; 2015) quando esclarecem que a hospitalidade pode ocorrer nas atividades comerciais. Assim, reforça a tese de que o ambiente físico, parte integrante do Servicescape, é um fator importante para formar as impressões de um consumidor (Schuster et al., 2016). Isso, porque este ambiente exerce influência sobre a criação da imagem do consumidor, especialmente nos negócios de serviços, como por exemplo, uma loja, restaurante e meios de hospedagens (Zeithaml et al, 1985; Upadhyaya et al., 2018; Stefanini et al., 2018).

A segunda hipótese H2 (As características hospitaleiras influenciam na percepção de servicescape), encontrou suporte no modelo, indicando que as características hospitaleiras (Hospitableness) importam ao cliente em sua percepção a respeito do ambiente físico e suas caracterizações (Servicescape). As condições desse ambiente, mesmo que de forma inconsciente, influenciam a sensação de bem-estar emocional do cliente, interferindo nas percepções, atitudes e comportamentos. Efeitos que podem ser estimulados usando itens que alcancem os cinco sentidos, provocando as emoções dos clientes que contribuem na percepção de hospitalidade. (Lovelock et al., 2011; Levy \& Weitz, 2000; Alves \& Marques, 2019).

Em seguida, a terceira hipótese H3 (As características hospitaleiras estão diretamente relacionadas a percepção de Hospitalidade do cliente), suportada no modelo deste estudo, confirmou que as experiências memoráveis nos ambientes comerciais do varejo são influenciadas pelos traços de personalidade dos colaboradores anfitriões. Isto, porque a Hospitableness, que são as características hospitaleiras do anfitrião (Telfer, 2004), influenciam a percepção do cliente em ser bem recebido no espaço comercial do varejo. Neste contexto, 
Margutti, A. N., Marques, R. B., \& Stefanini C. J. (set./dez. 2020). Hospitableness e servicescape na hospitalidade no contexto do varejo na cidade de São Paulo

confirmou-se o argumento de Pizam e Tasci (2019) quando apontaram que a cultura da hospitalidade pode ser amplamente aplicada nas organizações comerciais, reforçando, inclusive, que o local onde ocorre a interação interpessoal também tem um papel especial.

\section{Considerações finais}

Os conceitos de Hospitalidade, Hospitableness, Servicescape e Varejo foram empregados nesta pesquisa com o objetivo de avaliar a percepção da hospitalidade de clientes em estabelecimentos de alimentação, meios de hospedagens e lojas, não havendo na literatura a respeito do varejo de serviços no Brasil uma massa crítica robusta que possa alicerçar a análise. Esta característica inerente ao tema contribui para que o estudo a respeito do varejo e, em especial, da hospitalidade no varejo, instigue as pesquisadoras a avançarem com a investigação e a responder a seguinte questão: De que maneira o Hospitableness e o Servicescape influenciam na percepção de hospitalidade dos clientes, sobre os anfitriões, no varejo?

A amostra deste estudo foi predominantemente feminina (68,6\%), com uma faixa etária acima de 40 anos $(43,8 \%)$, casadas $(53,33 \%)$, com emprego formal $(48,57 \%)$ e pós-graduado $(56,73 \%)$. O ramo de estabelecimento mais escolhido para que a análise fosse realizada foi o de alimentação (66\%). Ressalta-se que os resultados apresentados são específicos desta amostra, e não há a pretensão de generalizá-lo, mas destaca-se a relevância do estudo nesta população.

A primeira hipótese (H1), se classificou como a que menos influencia, ainda que exista sinal de influência significativa, na percepção de Hospitalidade dos clientes sobre os anfitriões. A segunda hipótese $(\mathrm{H} 2)$, apresentou resultado significativo de relação entre Hospitableness e o Servicescape e, portanto, foi confirmada com valor significativo. A literatura de Servicescape indica a importância entre as relações que são estabelecidas entre os funcionários e os clientes (Bernard \& Bitner, 1981 como citado em Reimer \& Khuen, 2005; Schuster et al., 2016) indo ao encontro dos resultados da pesquisa. A terceira hipótese (H3) foi confirmada com resultados expressivos, comprovando para esta pesquisa que há relação entre Hospitableness e a percepção de Hospitalidade do cliente.

A percepção de Hospitalidade foi confirmada em todas as hipóteses com fator de impacto entre Hospitableness e Hospitalidade, conforme demonstrado estatisticamente. Parece correto afirmar que a percepção de Hospitalidade está relacionada às características do ambiente 
físico e de hospitalidade em estabelecimentos como, por exemplo, meio de hospedagem, restaurantes e lojas de varejo na cidade de São Paulo.

A pesquisa contou com limitações em decorrência de uma amostra restrita e homogênea, com ênfase na perspectiva dos respondentes dos estabelecimentos de alimentação. Recomendase a mesma investigação do ponto de vista do anfitrião, com o objetivo de ampliar a amostra e reforçar os achados desta pesquisa, assim como a utilização de entrevistas em profundidade, como instrumento de coleta de dados, com profissionais do setor.

Acredita-se que esta pesquisa possa contribuir para o melhor entendimento da percepção de hospitalidade dos clientes a partir dos conceitos de Servicescape e Hospitableness percebidos no ambiente do varejo. Espera-se que esta contribuição seja de utilidade para o mercado de varejo a partir de um novo olhar a respeito da hospitalidade.

\section{Referências}

Alves, C. A., \& Marques, R. B. (2019). Hospitalidad, emociones y experiencias en los servicios turísticos. Estudios y Perspectivas en Turismo, 28(2), 290-311.

Bitner, M. J. (1992). Servicescapes: The impact of physical surroundings on customers and employees. The Journal of Marketing, 56(2), 57-71.

Blain, M., \& Lashley, C. (2014). Hospitableness: the new service metaphor? Developing an instrument for measuring hosting. Research in Hospitality Management, 4(1/2), 1-8.

Camargo, L. O. L. (2004). Hospitalidade. São Paulo: Aleph.

Camargo, L. O. L. (2015). Os interstícios da hospitalidade. Revista Hospitalidade, 12 (Número Especial), 42-69.

Choi, M., Lee, J., \& Seo, A. (2018). Shopping destination competitiveness: scale development and validation. Journal of Travel \& Tourism Marketing, 35(8),1540-7306.

Chon, K.-S., \& Sparrowe, R. T. (2003). Hospitalidade: conceitos e aplicações. São Paulo: Pioneira Thomson Learning.

Cidade de São Paulo. (2019). Linha do tempo. Recuperado em 25 de junho de 2019 de http://cidadedesaopaulo.com/v2/pqsp/linha-do-tempo-landing-page/?lang=pt

Faria, I. C. S., \& Torres, R. G. (2015). Hospitalidade no varejo de moda feminina na cidade de São Paulo. Revista Hospitalidade. 12(Número especial), 298 - 323.

Gotman, A. (2003). Introdução. In A. Dencker, \& M. Bueno, M. (Org.). Hospitalidade: cenários e oportunidades. São Paulo: Pioneira Thomson Learning. 
Gotman, A. (2004). O Comércio da hospitalidade é possível? Revista Hospitalidade, 6(2), 3-27.

O'Gorman, K. D. (2007). Dimensions of hospitality: exploring ancient and classical origins. In C. Lashley, A. Morrison, \& P. Lynch (Eds.). Hospitality: a social lens. Amsterdam: Elsevier.

Grinover, L. (2002). Hospitalidade: um tema a ser reestudado e pesquisado. In C. M. M. (Org.). Hospitalidade: reflexões e perspectivas. São Paulo: Manole.

Grassi, M. (2004). Hospitalité. Passer lê seuil. In A. Montandon. Livre de l'hospitalité. Paris: Bayard.

Hair, J. F., Black, W. C., Babin, B. J., Anderson, R. E., \& Tatham, R. L. (2009). Multivariate data analysis. Pearson College Division.

Hair, J. F., Jr., Black, W. C., Babin, B. J., \& Anderson, R. E. (2010). Multivariate data analysis. Upper Side River: Prentice Hal

Instituto Brasileiro de Geografia e Estatística. (2010). Cidades: São Paulo. 2010. Recuperado em 25 de março de 2019 de https://cidades.ibge.gov.br/brasil/sp/saopaulo/panorama

Instituto Brasileiro de Geografia e Estatística. (2017). Pesquisa de serviços em hospedagem - 2016. Rio de Janeiro: IBGE.

Kotler, P. (2000). Administração de marketing: a edição do novo milênio. São Paulo: Prentice Hall.

Kotler, P., Kartajaya, H., \& Setiawan I. (2017). Marketing 4.0: mudança do tradicional para o digital. Coimbra: Actual.

Las Casas, A. (2004). Marketing de varejo. São Paulo: atlas.

Lashley, C. (2015). Hospitalidade e hospitabilidade. Revista Hospitalidade, 12(Número especial), 70-92.

Lashley, C. (2004). Para um entendimento teórico. In C. Lashley \& A. Morrison (Orgs.). Em busca da Hospitalidade: perspectivas para um mundo globalizado. Barueri: Manole.

Lashley, C., Lynch, P., \& Morrison, A. (Eds.). (2007). Hospitality: a social lens. Amsterdam: Elsevier.

Levy, M., \& Weitz, B. (2000). Administração de varejo. São Paulo: Atlas.

Lockwood, A., \& Jones, P. (2004). The management of hotel operations. New York: Cengage Learning. 
Margutti, A. N., Marques, R. B., \& Stefanini C. J. (set./dez. 2020). Hospitableness e servicescape na hospitalidade no contexto do varejo na cidade de São Paulo

Lovelock, C., Wirtz, J., \& Hemzo, M. (2011). Marketing de serviços: pessoas, tecnologia e estratégia. (7a ed.). São Paulo: Pearson Prentice Hall.

Marques, R. B. (2018). Características hospitaleiras do anfitrião de meios de hospedagem. Revista Hospitalidade. 15(1), 214-226.

Mattar, F. (2011). Administração de varejo. Rio de Janeiro: Elsevier.

Moretti, S., \& Pinotti, R. (2018). Hospitalidade e intenção de recompra na economia compartilhada: um estudo com equações estruturais em meios de hospedagem alternativos. Revista Turismo em Análise, 29(1), 1-18.

Mulhern, F. J. (1997). Retail marketing: From distribution to integration. International Journal of Research in Marketing, 14(2), 103-124.

Mullins, L. (2001). Gestão da hospitalidade e comportamento organizacional. (4a. ed.). Porto Alegre: Bookman.

Nilsson, E., \& Ballantyne, D. (2014). Reexamining the place of servicescape in marketing: a service-dominant logic perspective. Journal of Services Marketing, 28(5), 374-379.

Parente, J. (2000). Varejo no Brasil. São Paulo: Atlas.

Pizam, A., \& Tasci, A. (2019). Experiencescape: expanding the concept of service with a multi-stakeholder and multi - disciplinary approach. International Journal of Hospitality Management, 76, 25-37.

Powers, T., \& Barrows, C. W. (2004). Administração no setor de hospitalidade: turismo, hotelaria, restaurante. São Paulo: Atlas.

Prasad, N., \& Seshanna, S. (2015). Retail management. Nova Déli: Mc Graw Hill Education.

Reimer, A., \& Kuehn, R. (2005). The impact of servicescape on quality perception. Eur. $J$. Mark., 39(7/8), 785-808.

Rocha, A. B. V. (2018). A experiência de compra do consumidor popular no varejo de moda. Anais do $11^{\circ}$ Congresso Latino-Americano de Varejo e Consumo - CLAV. São Paulo, SP, Brasil.

Schuster, M., Dias, V., \& Battistella, L. (2016). Marketing de intangíveis: a servicescape e o uso das evidências físicas para a projeção dos ambientes de serviço. Revista Tourism \& Management Studies, 12(2), 128-134.

Sociedade Brasileira de Varejo e Consumo. (2019). O papel do varejo na economia brasileira. Recuperado em 04 de abril de 2019 de http://sbvc.com.br/o-papel-do-varejona-economia-brasileira-atualizacao-2019/ 
Stefanini, C. J., Alves, C. A., \& Marques, R. B. (2018). Vamos almoçar? Um estudo da relação hospitalidade, qualidade em serviços e marketing de experiência na satisfação dos clientes de restaurantes. Revista Brasileira Pesquisa em Turismo, 12(1), 57-79.

Tasci, A. D. A., \& Semrad, K. J. (2016). Developing a scale of hospitableness: A tale of two worlds. International Journal of Hospitality Management, 53, 30-41.

Telfer, E. (2004). A filosofia da "hospitalidade". In C. Lashley, \& A. Morrison (Org). Em busca da hospitalidade: perspectivas para um mundo globalizado. Barueri: Manole.

Upadhyaya, M., El-Shishini, H., Aziz, W., \& Kumar, V. (2018). Retailscape: an exploration of the relevant dimensions and their impact on consumers' behavioral intentions. Journal of Business and Retail Management Research, 12(4), 208-220.

Vergara, S. (2005). Projetos e relatórios de pesquisa em administração. São Paulo: Atlas.

Wakefield, K., \& Blodgett, J. (2016). Retrospective: the importance of servicescapes in leisure service settings. Journal of Services Marketing, 30(7), 686-691.

Zeithaml, V. A., Bitner, M., \& Gremler, D. (2011). Marketing de serviços: a empresa com foco no cliente. (5a. ed.). Porto Alegre: Bookman.

Zeithaml, V., Parasuraman, A., \& Berry, L. (1985). Problems and strategies in services marketing. Journal of Marketing, 49(2), 33-46. 